\title{
Arrow: jogo digital para apoio à aprendizagem de vetores
}

\author{
Glice Rocha Pires ${ }^{1}$, Carlos Artur Guimarães ${ }^{1}$, Jeanne da S. B. Bulcão ${ }^{1}$, Ana \\ Patrícia R. Calisto ${ }^{1}$, Charles A. Galvão Madeira ${ }^{1}$, André M. C. Campos ${ }^{2}$ \\ ${ }^{1}$ Instituto Metrópole Digital - Universidade Federal do Rio Grande do Norte(UFRN)- \\ Natal - RN - Brazil \\ 2 Departamento de Informática e Matemática Aplicada - Universidade Federal do Rio \\ Grande do Norte (UFRN) - Natal - RN - Brazil \\ \{glice.rp, arturguimaraes, jeannebulcaol,patcalistrato\}@gmail.com, \\ charles@imd.ufrn.br, andre@dimap.ufrn.br
}

Abstract. Students have been presenting low performance in curricular components such as Vectors and Analytical Geometry within Brazilian universities. This work describes the elaboration of a prototype of an educational game whose objective is to support the learning process of Vectors, one of the pillars of these disciplines. It is portrayed here the form of development of the game, its operation and its experimentation with the target audience of the game. The game was tested with students from technical and higher education. The results of the analysis confirmed the students interest in the game approach and proved to be a good incentive for the development of vector-related skills.

Resumo. Alunos têm apresentado baixo desempenho em componentes curriculares como Vetores e Geometria Analítica dentro de universidades brasileiras. Este trabalho descreve a elaboração de um protótipo de jogo educativo cujo objetivo é auxiliar na aprendizagem do conteúdo de vetores, um dos pilares dessas disciplinas. Neste aspecto, retrata-se aqui a forma de desenvolvimento do jogo, seu funcionamento e sua experimentação realizada com público alvo do jogo. O jogo foi testado com estudantes do ensino técnico e superior. Os resultados da análise confirmaram o interesse dos alunos na abordagem de jogos e mostrou-se satisfatório como forma de incentivo ao desenvolvimento das habilidades relacionadas a vetores.

\section{Introdução}

Em cursos de graduação da área de Ciências Exatas, é comum encontrar turmas em que parte dos alunos apresenta limitações na internalização de conteúdos abstratos e matemáticos. Em um estudo realizado pela Universidade Estadual de Minas Gerais (UEMG), $41 \%$ dos alunos de uma turma de Geometria Analítica e Álgebra Linear relataram dificuldades na visualização tridimensional de conteúdos, apresentando um desempenho acadêmico muito abaixo do esperado, com nota média de apenas 33,4\% em avaliações [Simões et al. 2014].

Em uma universidade federal do Brasil, alvo desta pesquisa, foi realizada uma consulta relacionada a aprovação na disciplina de Vetores e Geometria Analítica (VGA) através do portal de dados abertos da instituição. Nesta disciplina, na qual é trabalhado o conteúdo de vetores e suas aplicações geométricas, foi observado um alto índice de reprovação (Tabela 1) entre aqueles que não trancaram a matrícula. 
VIII Congresso Brasileiro de Informática na Educação (CBIE 2019)

Anais do XXV Workshop de Informática na Escola (WIE 2019)

Tabela 1. Percentual de aprovação e reprovação em VGA na referida instituição

\begin{tabular}{|c|c|c|c|}
\hline \multicolumn{2}{|c|}{ MATRICULADOS } & Aprovados & Reprovados \\
\hline 2017.1 & 87 & $48,28 \%$ & $51,72 \%$ \\
\hline 2017.2 & 162 & $50,62 \%$ & $49,38 \%$ \\
\hline
\end{tabular}

Existem ferramentas digitais que podem auxiliar na visualização da representação geométrica de equações matemáticas, como o GeoGebra, o Matplotlib e o site WolframAlpha. Porém, tradicionalmente, a aplicabilidade do conteúdo e contextualização dos exercícios de fixação da matéria é baixa. Este fato reflete uma realidade frequente nos cursos da área de Exatas, em que geralmente se enfatiza formas tradicionais de se resolver problemas, sem auxílio, por exemplo, de instrumentos lúdicos [Junior e Colvara 2010].

Diante deste cenário, o uso de uma tecnologia educacional que leve em consideração os conceitos trabalhados em sala de aula, num contexto relevante, lúdico e motivador para o aluno [Nascimento 2007] poderá contribuir para uma aprendizagem significativa [Ausubel 1982], que resultará em uma melhor concretização do aprendizado de conteúdos abstratos. A literatura tem sugerido que a utilização de jogos digitais como recurso didático pode aumentar a motivação e, consequentemente, a aprendizagem dos alunos.

Os Jogos Digitais Educacionais vêm ganhando notoriedade na escola. Ribeiro et al (2014) aponta que o crescimento em 10 anos (2004 - 2014) das publicações sobre o tema em meio acadêmico no Brasil alinha-se, provavelmente, com a notoriedade mencionada. Observou-se que, apesar do crescente uso do jogo como parte integrante do processo ensino aprendizagem, para diferentes áreas do conhecimento, a elaboração, o desenvolvimento e a aplicação desses jogos acontecem, ainda, de forma desvinculada às Teorias de Aprendizagem.

Recentemente Silva [2017] publicou que, em geral, os jovens que ingressam no ensino superior, jogaram ou jogam algum tipo de jogo digital. Essa tecnologia proporciona vivências e experiências por vezes muito mais envolventes do que a realidade. Esse crescente interesse pelos jogos digitais não abrange apenas os estudantes, mas também os educadores, uma vez que os jogos despertam o interesse dos alunos. Isto, porque, conceitos e ideias na forma de jogo digital tendem a ser aprendidos pelos alunos de forma mais natural e dinâmica, contrapondo-se à cultura predominante do ensino superior, na qual a aprendizagem está centrada na memorização dos conteúdos e na sua avaliação quantitativa. Essa cultura do ensino superior distancia-se da construção de conhecimentos para sua aplicação na resolução de problemas reais.

Assim, os jogos educativos têm a função de motivar, explorar e auxiliar atividades educacionais fornecendo assim novas alternativas de aprendizagem de forma a proporcionar novas abordagens de ensino [Mattar 2010].

O presente trabalho apresenta o game Arrow. Um protótipo de jogo digital de apoio à aprendizagem do conteúdo de vetores, trabalhado na disciplina de Vetores e 
VIII Congresso Brasileiro de Informática na Educação (CBIE 2019)

Anais do XXV Workshop de Informática na Escola (WIE 2019)

Geometria Analítica, Geometría Analítica e Álgebra Linear, utilizando uma abordagem dinâmica, lúdica e contextualizada.

\section{Trabalhos relacionados}

Para planejamento, organização e elaboração do Jogo Arrow foram consultados alguns trabalhos acadêmicos semelhantes e/ou que colaboraram com a proposta do artefato. Nos trabalhos consultados, destacam-se aqueles que colaboraram diretamente nos aspectos relativos à intencionalidade educativa, a utilização da tecnologia empregada e a relação com o nível de ensino do jogo proposto.

Dentre os artigos, destaca-se Santos et al. [2015] que objetivou avaliar dois jogos educativos, em aspectos computacionais de interface e aspectos pedagógicos e constatou que os jogos tiveram resultados positivos em ambos os aspectos, a partir da abordagem de avaliação GameFlow, Lori e Kirkpatrick, focado em perspectiva qualitativa e quantitativa, para jogos dessa natureza; Silva et al [2016] que discorre sobre a criação e utilização do Math \& Magic (RPG) como instrumento de aproximação pedagógica de conteúdos no ensino superior na disciplina de Cálculo; e, Junior et al [2018] com o jogo FlashMath que tinha como objetivo apresentar conteúdos de lógica de programação para os alunos de um curso técnico em informática.

No processo de análise desses trabalhos foram identificados possibilidades pedagógicas dos jogos e alguns caminhos a serem seguidos para o alcance da proposta do jogo a ser elaborado. A análise dos artigos apontou caminhos pedagógicos para a introdução do conteúdo de vetores e a tecnologia a ser utilizada na implementação do jogo Arrow.

\section{Metodologia}

O grupo participante do processo de sistematização da proposta do jogo, da escrita do game design e da programação era composto por um pedagogo, um licenciado em informática, um licenciado em filosofia e um bacharel em tecnologia da informação (TI). Cada profissional ficou responsável por uma parte do processo de criação do jogo. Professores colaboradores colaboraram na organização e validação da ideia do jogo. Os de TI foram direcionados para a construção do artefato digital.

O jogo foi implementado e validado, posteriormente, por meio de aplicação junto a ex-alunos e possíveis futuros alunos da disciplina Vetores e Geometria Analítica (VGA). Para a construção do jogo, foram divididas as telas de exibição, a partir das ações que se esperava do avatar controlado pelo jogador. $O$ jogador utiliza os conceitos de vetores matemáticos para desenvolvimento de estratégias de ataque, isto é, raciocinando quanto à aplicação matemática de vetores, ele deve usar o mouse para escolher quais vetores o ajudarão em sua missão.

\subsection{História}

Arrow é um mini jogo influenciado pelo estilo Tower Defense. Nesse estilo de jogo, o jogador controla um personagem responsável por se defender dos inimigos a partir da sua base (Torre de Defesa). A proposta do jogo é relacionada a vetores e parte das mecânicas apresentam conceitos de eixos e coordenadas cartesianas. 
O game Arrow consiste em acertar alvos (inimigos alienígenas) expostos na tela. O jogador precisa, a partir de uma base de controle, identificar qual a posição do alvo em relação à origem (base), selecionando os vetores que devem ser escolhidos para ele ter sucesso no jogo. O jogador é um terráqueo que pode lançar setas destruidoras de inimigos a partir de uma base espacial. Ele escolhe onde a seta irá parar para detonar uma bomba em um inimigo, determinando seu deslocamento por meio de um vetor.

As setas são apresentadas e gerada uma visualização no campo de batalha, o jogo é permeado pelas escolhas do jogador ao escolher entre as opções de vetores. Em caso da escolha do vetor correto é combatido o inimigo, em caso de erro é necessário definir uma nova estratégia.

Para criação do jogo, foi desenvolvido um Game Design Canvas ${ }^{1}$ em que desenvolveu-se a proposta inicial do jogo: o conceito do uso de vetores para desenvolvimento de estratégias e a jogabilidade através de flechas.

\subsection{Desenvolvimento e aplicação}

O software foi implementado via a ferramenta de desenvolvimento Construct 3. Esta foi escolhida pela capacidade de prototipagem rápida utilizando linguagem de blocos, para desenvolvimento de jogo 2D.

\subsection{O Jogo Implementado}

O jogo apresenta uma tela de fundo montanhoso em sua abertura, sugerindo ao usuário a ideia de altitude elevada. Quando o usuário começa o jogo, são exibidos na tela textos que introduzem o assunto de vetores (Figura 1):

- "Ola! Voce sabe como os vetores se comportam?";

- "Você sabia que a palavra vetor vem do verbo latino 'vehere', que significa transportar?";

- "Ao clicar em START, você vai ver como e divertido carregar objetos usando vetores!".

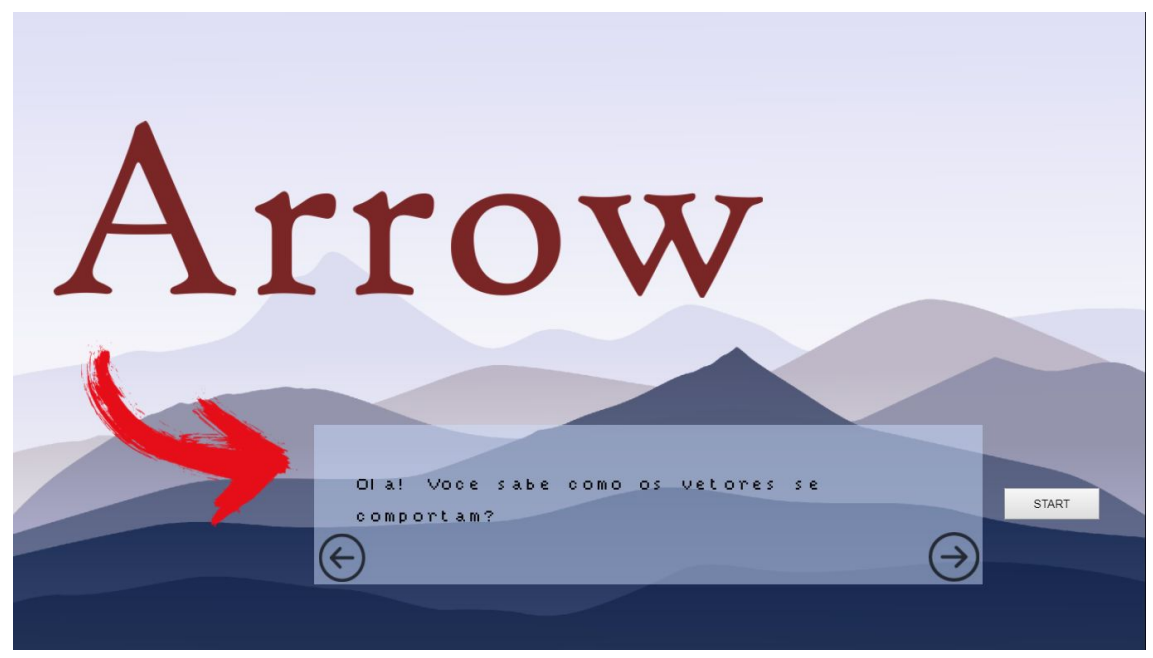

Figura 1. Diálogo inicial do jogo - introduzindo o assunto Vetores

\footnotetext{
${ }^{1}$ http://bit.ly/2Y20BaE
} 
VIII Congresso Brasileiro de Informática na Educação (CBIE 2019)

Anais do XXV Workshop de Informática na Escola (WIE 2019)

Clicando em 'START", é exibida a apresentação do contexto através de uma narrativa. O personagem, a partir de sua base de comando, à vista inimigos que começam a invadir a atmosfera terrestre vindos do espaço. Ele precisa selecionar os vetores que irão levar bombas destruidoras até a localização exata dos inimigos no céu, impedindo a invasão alienígena.

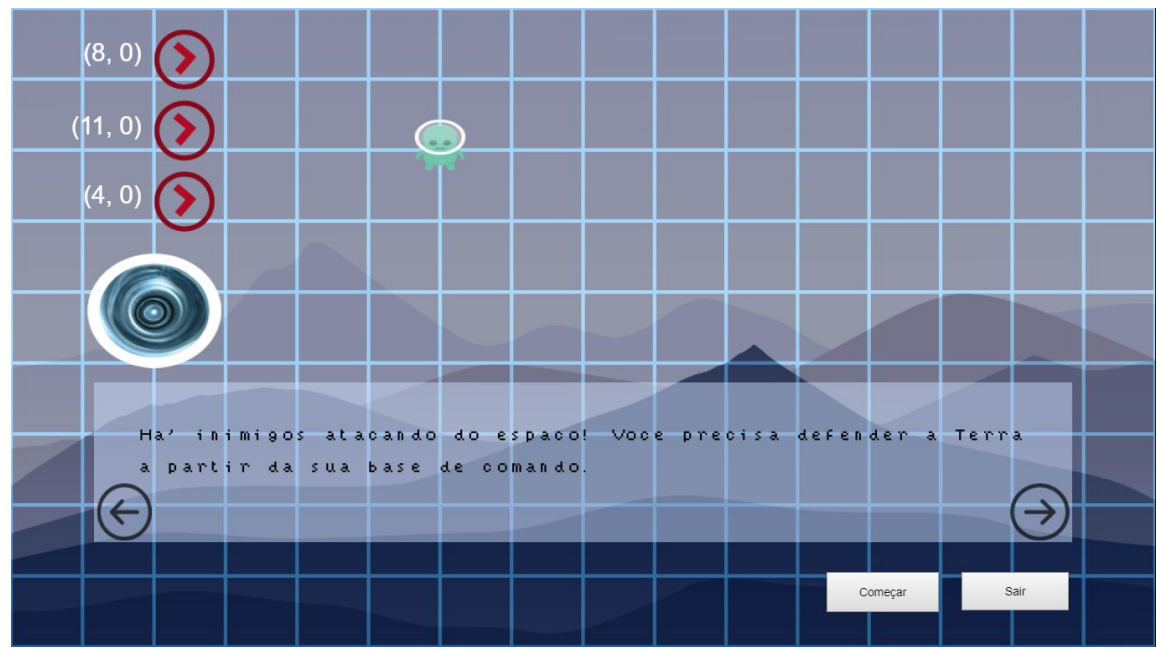

Figura 2. Tela do texto instrucional

O jogo orienta o usuário a: (1) utilizar a grade azul na tela como guia para encontrar a localização do inimigo, e (2) considerar a base de comando (representada por um círculo) como a origem do vetor - ou seja, a posição 0 nos eixos X e Y.

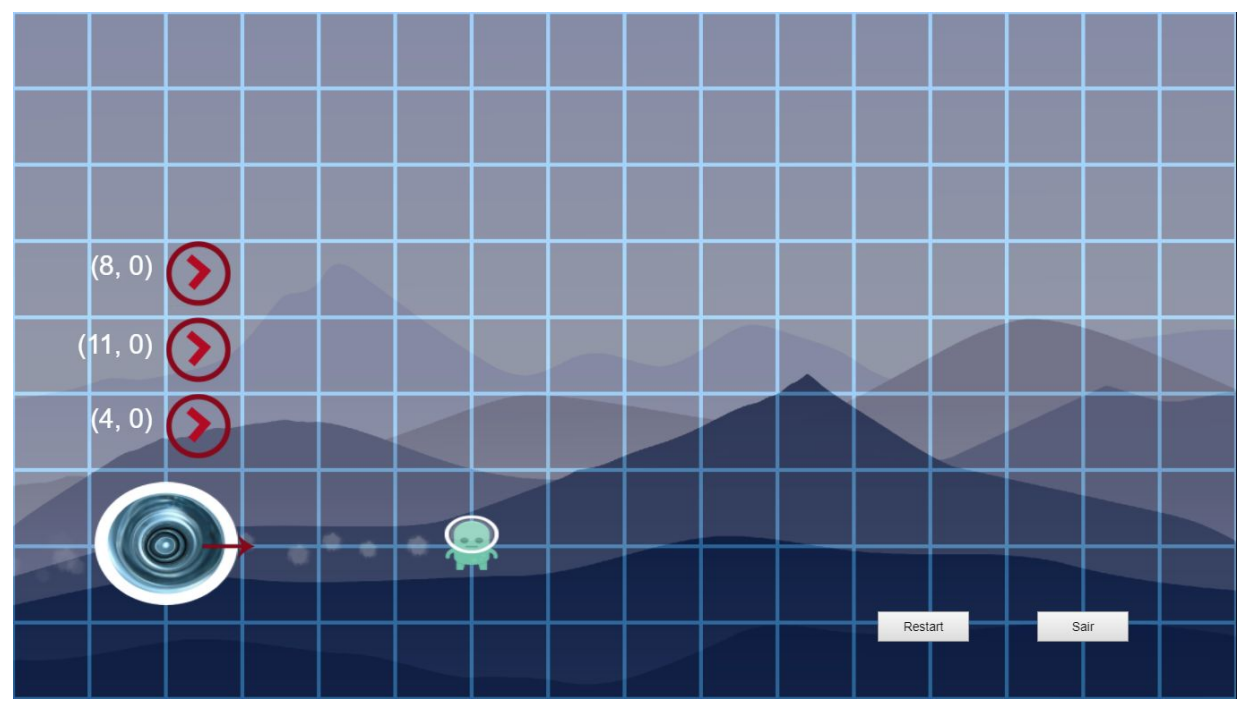

Figura 3. Representação de deslocamento no eixo X

$\mathrm{O}$ vetor, representado por uma seta vermelha, transporta uma bomba de sua origem (base) até o seu alvo. Este, por sua vez, é determinado por um par de coordenadas que o jogador deve selecionar dentre as opções fornecidas a ele (par de valores entre parênteses). 
VIII Congresso Brasileiro de Informática na Educação (CBIE 2019)

Anais do XXV Workshop de Informática na Escola (WIE 2019)

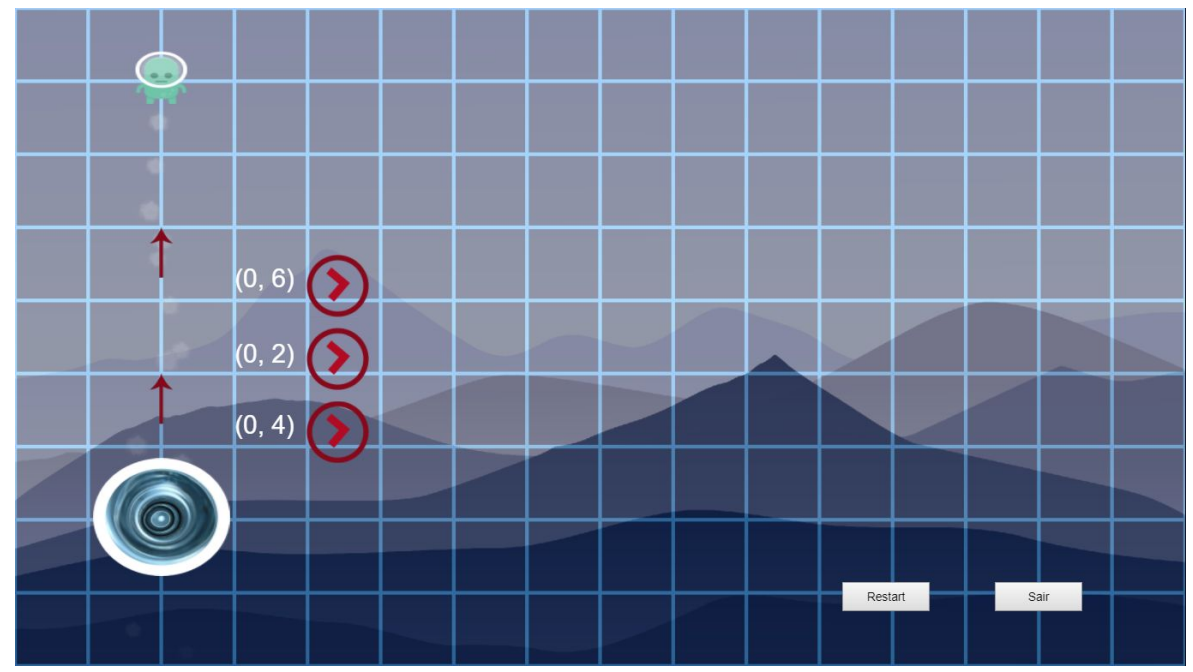

Figura 3. Representação de deslocamento no eixo $Y$

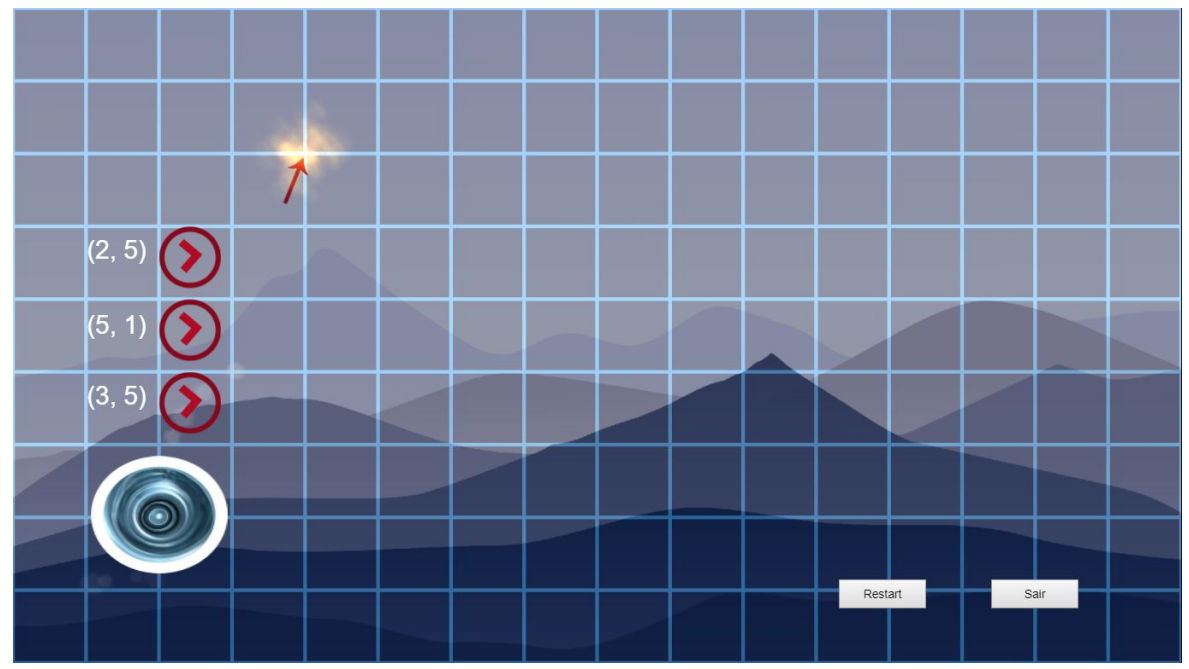

Figura 4. Representação de deslocamento nos eixos $\mathrm{X}$ e $\mathrm{Y}$.

O jogo conclui com frases cujo propósito é gerar satisfação no usuário e incentivá-lo a estudar o conteúdo de vetores:

- "Parabéns! Você concluiu sua missão!"

- "Você já entende como os vetores se comportam!"

- "Agora, vamos aos estudos!"

A validação do Arrow foi realizada através de teste com alunos-jogadores e aplicação de questionário com os alunos. Realizado em ambiente uniforme, o jogo foi testado visando características hegemônicas como: o laboratório de informática padronizado, orientações padronizadas ao jogo e resposta do questionário. $\mathrm{O}$ teste foi aplicado em uma universidade pública em dois momentos: (1) pré-teste e (2) teste. Os jogadores são alunos de cursos de nível superior ou técnico em TI.

O jogo foi aplicado com dois grupos: (1) alunos do curso técnico em T.I. e (2) alunos da graduação em Bacharelado em Tecnologia da Informação. Durante o experimento, os alunos realizaram a jogatina seguida do preenchimento do questionário. 
VIII Congresso Brasileiro de Informática na Educação (CBIE 2019)

Anais do XXV Workshop de Informática na Escola (WIE 2019)

No momento de experimentação, foi sugerido aos jogadores que tentassem não errar o alvo, para evitar que eles apenas clicassem nas setas de forma impensada e não parassem para observar a relação entre o alvo e as opções de coordenadas exibidas na tela.

O questionário foi realizado usando perguntas fechadas, com única alternativa e escala liketer com 5 pontos e 3 perguntas abertas. As perguntas foram divididas por categorias: (A) Os aspectos Culturais do Jogador, (B) Seu conhecimento em Vetores, (C) o Grau de imersão no Jogo e (D) Opinião didática. Posteriormente foi realizada uma entrevista aberta com voluntários onde era possível realização de sugestões ou críticas. O tempo médio da jogatina foi de 5 minutos, da entrevista idem e o formulário os alunos terminaram em cerca de 3 minutos. As questões apresentadas foram as seguintes:

Table 2. Perguntas do questionário aplicado a alunos

\begin{tabular}{|l|l|}
\hline & \multicolumn{1}{|c|}{ Descrição } \\
\hline Q1 & Qual a sua idade? \\
\hline Q2 & Qual sua escolaridade? \\
\hline Q4 & Qual o seu curso? \\
\hline Q5 & Que cursou (ou está cursando) a disciplina de VGA? \\
\hline Q6 & $\begin{array}{l}\text { Qual(is) dispositivo(s) você costuma usar para jogar } \\
\text { jogos digitais? }\end{array}$ \\
\hline Q7 & $\begin{array}{l}\text { Responda o quanto você concorda com as } \\
\text { afirmações abaixo. }\end{array}$ \\
\hline Q8 & $\begin{array}{l}\text { Enquanto jogava, você sentiu perder a noção do } \\
\text { tempo: }\end{array}$ \\
\hline Q9 & Você se sentiu desafiado durante o jogo: \\
\hline Q10 & $\begin{array}{l}\text { Você notou a aplicabilidade de alguma habilidade } \\
\text { ou competência educacional no jogo: }\end{array}$ \\
\hline Q11 & Você se divertiu durante o jogo: \\
\hline Q12 & Você teve controle durante o jogo: \\
\hline Q13 & O jogo contribui para o aprendizado de vetores: \\
\hline Q14 & Conte algo que chamou sua atenção no jogo. \\
\hline Q15 & $\begin{array}{l}\text { Há algo do qual você não gostou ou melhoraria } \\
\text { nele? Se possível, especifique abaixo. }\end{array}$ \\
\hline Q16 & $\begin{array}{l}\text { Gostaria de deixar mais algum comentário sobre o } \\
\text { jogo? Escreva-o abaixo. }\end{array}$ \\
\hline
\end{tabular}

\section{Resultados e discussão}

A teoria do Flow, criada por Csikszentmihalyi (1990) busca identificar e compreender o grau de felicidade e satisfação no desenvolvimento de uma atividade. Esse grau de satisfação quando alcançado corresponde a uma enorme imersão caracterizando um estado de Flow. Na área de jogos a teoria do Flow é bastante utilizada como forma de compreensão e pesquisa quanto ao grau de imersão de jogadores em relação uma determinada experiência de jogo.

Para o jogo Arrow foi utilizado questões quanto avaliação do jogo visando identificação do grau de flow dos jogadores em relação ao jogo (questões Q8 e Q9) e a experiência educacional a que se propunha o jogo. 
A idade dos jogadores foram de 15 aos 34 anos, possuindo diversos níveis de escolaridade, com concentração de $38.1 \%$ de alunos do ensino médio. Os jogadores todos de cursos de Tecnologia da Informação e a maioria de $71 \%$ estudaram conteúdos de Vetores e Geometria Analítica. Cerca de 90\% são jogadores assíduos de games digitais.

A grande maioria dos jogadores (18 dos 21) concordam que os jogos podem contribuir para melhorar o processo de ensino aprendizagem. Destes, 13 sentiram perder a noção do tempo enquanto jogavam, o que configura como algo positivo para avaliação do flow dos jogadores, o jogo configura-se como atividade lúdica. Não existe sumidade quanto grau de desafio do jogo, deve-se pelo fato do jogo conter elementos introdutórios ao conteúdo de vetores. A totalidade dos jogadores percebeu conteúdo didáticos nos jogos. Também foi possível mensurar o grau de divertimento envolvido na jogatina e o caráter educacional do jogo. Dos entrevistados, 14 afirmaram se divertir durante o jogo e 16 afirmaram que o jogo contribuiu para seu aprendizado relacionado a vetores.

O jogo teve 3 perguntas abertas: (1) Conte algo que chamou sua atenção no jogo; (2) Há algo do qual você não gostou ou melhoraria nele? Se possível, especifique abaixo; e (3) Gostaria de deixar mais algum comentário sobre o jogo? As perguntas abertas, obtiveram dados sobre brevidade do jogo, mesmo assim, muito elogiado quanto Game Design e a forma de passar o conteúdo de vetores.

É viável a aplicação do mesmo em sala de aula se forem desenvolvido outras fases, com mais elementos de jogos para enriquecimento do jogo deixando ele mais divertido com mais elementos visando diversão no jogo e prolongamento da histórica com mais elementos de vetores. Deve-se acrescentar boss, tempo, capacidade de duelar e mais inimigos.

\section{Considerações finais}

Os jogos eletrônicos, hoje digitais, apresentam uma interface que motiva os estudantes pela sua capacidade de projetar uma realidade em que os jogadores podem simular e atuar com características diferentes de personagens, onde há feedback imediato e as metas são claras e desafiadoras.

O jogo Arrow foi elaborado projetando em si as expectativas dos alunos para abstração e compreensão sobre vetores matemáticos. Quanto a este ponto, o jogo alcançou seu objetivo. Os alunos demonstraram interesse no jogo, porém apontaram melhorias necessárias em relação a mecânica do jogo, tais como: brevidade, velocidade, interação entre o spriter e os inimigos. Em relação aos aspectos pedagógicos os alunos que utilizaram os jogos indicam que o jogo sensibiliza com qualidade o tema vetores.

As limitações identificadas no protótipo foram sistematizadas e, posteriormente, serão implementadas nas próximas versões. Será inserido outras fases, níveis de dificuldade e mais obstáculos para o sprite destruir.

Arrow confirma a possibilidade de uso de de jogos como metodologias educacionais, podendo ser utilizado como alternativa pedagógica para aprendizado dos alunos, desenvolvimento de estímulo ao aprendizado conteudista e de internalização da ementa. Além de possibilitar um melhor tratamento de conceitos de vetores de forma 
VIII Congresso Brasileiro de Informática na Educação (CBIE 2019)

Anais do XXV Workshop de Informática na Escola (WIE 2019)

concreta através da manipulação do conteúdo, representação visual e criação lúdica do conhecimento, o que no ensino tradicional é possível apenas de forma abstrata.

A contribuição do trabalho consta da apresentação de um jogo didático para uso uso como ferramenta de ensino e aprendizagem na área de vetores para alunos de nível superior, podendo ser um importante recurso para melhoria do aprendizado dos alunos, por possibilitar uma abordagem inovadora para conhecimento do conteúdo, pois é possível aos alunos desenvolverem seus conhecimentos de forma concreta ao jogar Arrow e relacionar os conteúdos de vetores imersos no próprio jogo.

\section{Referências}

Ausubel, D. P. (1982) A Aprendizagem Significativa: A Teoria De David Ausubel. São Paulo: Moraes.

Csikszentmihalyi, M. (1990). Flow: the psychology of optimal experience. New York, NY, USA: Harper \& Row.

Junior, Niltom Vieira; Colvara, Laurence Duarte. (2010) Os modelos mentais de alunos em relação a vetores em duas e três dimensões: uma análise da dinâmica da aprendizagem e da inadequação das avaliações tradicionais. Ciências \& Cognição, v. 15, n. 2, p. 55-69.

Junior, R. M., Vieira, F., \& Moreira, E. (2018, October). FlashMath: O jogo para o ensino de operações lógicas e matemáticas. In Anais dos Workshops do Congresso Brasileiro de Informática Na Educação (Vol. 7, No. 1, P. 221).

Mattar, J. (2010). Games em educação. Pearson Educación.

Nascimento, A. C. A. (2007) Objetos de Aprendizagem: a Distância entre a Promessa e a Realidade, p. 135-145. In: Objetos de Aprendizagem: uma Proposta de Recurso Pedagógico, Organização: C. L. P. Prata e A. C. A. de A Nascimento, Brasília: MEC, SEED, <http://www.oei.es/tic/livro.pdf>.

Ribeiro, J. L. P. (1999). Escala De Satisfação Com O Suporte Social (Esss). Análise Psicológica, 17(3), 547-558.

Ribeiro, R. J. Teorias De Aprendizagem Em Jogos Digitais Educacionais: Um Panorama Brasileiro. Paraná: Renote, 2015.

Santos, Carla M. Claudino S. dos et. all. Educação e Tecnologia: Novas possibilidades, novos caminhos. Edição 1. Ano 2018.

Savi, R. Von, W.C. G., Ulbricht, V. \& Vanzin, T. (2010). Proposta de um modelo de avaliação de jogos educacionais. Renote, 8(3).

Silva, K., Rocha, P. H., Mesquita, R. P., \& Marcondes, G. A. Math \& Magic: Uma Proposta Lúdica Para Auxílio No Ensino De Cálculo.

Silva, L. A. Uso Dos Jogos Digitais Em Disciplinas Científicas Do Nível Superior: Teorias E Argumentos Para Sua Implementação. Florianópolis: Enpec, 2017.

Silva, Rodrigo Ribeiro; Fernandes, Juliana; SANTOS, Rodrigo. Panorama da Utilização de Jogos Digitais no Ensino de Programação no Nível Superior na Última Década: Uma Revisão Sistemática da Literatura. In: Brazilian Symposium on Computers in 
VIII Congresso Brasileiro de Informática na Educação (CBIE 2019)

Anais do XXV Workshop de Informática na Escola (WIE 2019)

Education (Simpósio Brasileiro de Informática na Educação-SBIE). 2018. p. 535.

Silva, T. Melo, J. Tedesco, P.. A Teoria Do Flow Na Contribuição Do Engajamento Estudantil para apoiar a escolha de jogos no ensino de programação. In: Brazilian Symposium on Computers in Education (Simpósio Brasileiro de Informática na Educação-SBIE). 2015. p. 607.

Simões, A. C.; Hespanhol, A. C. F.; Lemos, A. M.; Assis, H. A.; Teixeira, J. J. M; Ferreira, J. N. (2014) Aplicação de softwares matemáticos no ensino da geometria analítica e álgebra linear. Engenharia: múltiplos saberes e atuações. Juiz de Fora, MG.

Valente, J.A. (1993). "Formação De Profissionais Na Área De Informática Em Educação". In: J.A. Valente (Org.), Computadores E Conhecimento: Repensando A Educação. Primeira Edição, Campinas: Nied - Unicamp, P. 114-134. 